\title{
Return threshold model analysis of two stock markets: Evidence study of Italy and Germany's stock returns
}

\author{
Wann-Jyi Horng, Yu-Cheng Chen, Weir-Sen Lin \\ (Department of Hospital and Health Care Administration, Chia Nan University of Pharmacy and Science, Tainan 71710, Taiwan)
}

\begin{abstract}
This paper discusses the model construction and the association between the Italy and the Germany's stock markets. The period of study data is from January 3, 2000 to June 30, 2008. This paper also utilizes Student's $t$ distribution to analyze the proposed model. The empirical results show that the two stock markets are mutually affected each other, and the dynamic conditional correlation (DCC) and the bivariate asymmetric-GARCH $(1,2)$ model is appropriate in evaluating the relation between them. The empirical result also indicates that Italy and Germany's stock markets show a positive relationship. The average value of correlation coefficient equals to 0.8424 , which implies that the two stock markets return volatility have a synchronized influence on each other. In addition, the empirical result also shows that there is an asymmetrical effect between Italy and the Germany's stock markets, and demonstrates that the good news and bad news of the stock returns' volatility will produce the different variation risks for Italy and the Germany's stock price markets.
\end{abstract}

Key words: stock market returns; GARCH model; asymmetric effect; GJR-GARCH model; bivariate asymmetric GARCH model

\section{Introduction}

As is known to all, Germany is one of big eight industrial countries in the global economical financial system and also has been very influential in the global economy. Germany is also a country with high production and in high income levels, and its social welfare is extremely developed and the life is extremely wealthy. For example, the domestic production gross achieves to 2,249 billion Euros in 2005, which grows 0.9\% compared with in 2004 (data source: The Federation Statistics Bureau). In addition, the export values of German enterprises are occupied $1 / 3$ of the domestic production gross. When the investor has an investment in international stock market, he/she will usually care about the international capital, the motion situation, the international politics and the economical situation change, in particular, Italy stock market change. There is a close relationship for Italy based on the trade and the circulation of capital with Germany, but Germany is also a powerful global economical nation. Therefore, the relationship between Italy’s stock market and Germany’s stock market is worth further discussion.

With the existence of many return volatility methods (e.g. autoregressive moving average (ARMA) model), researchers commonly used to investigate the relations between two stock markets. Engle (1982) proposed the

Wann-Jyi Horng, Ph.D., associate professor, Department of Hospital and Health Care Administration, Chia Nan University of Pharmacy and Science; research fields: statistics, econometrics, data analysis.

Yu-Cheng Chen, Ph.D., associate professor, Department of Hospital and Health Care Administration, Chia Nan University of Pharmacy and Science; research fields: statistics, data analysis, data mining.

Weir-Sen Lin, Ph.D., associate professor, Department of Hospital and Health Care Administration, Chia Nan University of Pharmacy and Science; research fields: health care management, biostatistics. 
autoregressive conditionally heteroskedasticity (ARCH) model and Bollerslev (1986) proposed the generalized autoregressive conditionally heteroskedasticity (GARCH) model. According to them, this kind of model is comparatively better at catching the financial property while the conditional variance does not have the fixed characteristic. Nelson (1990) looked at stock price changes and discovers that there are both positive and negative relationships with the future stock price volatility. The GARCH model supposes that the settled time conditional variance is a function of conditional variance and an error term square term's time lags. Therefore, error term's positive and negative values do not respond to its influence on the conditional variance equation. The conditional variance can only change along with the error term's value, but cannot go along with the error term's positive and negative changes. To improve this flaw, Nelson (1991) presented an exponential GARCH model and Glosten, Jagannathan and Runkle (1993) gave a threshold GARCH model. These models are so-called the models of asymmetric-GARCH. Their models are adopted by many scholars, while researching on the issue of asymmetric problems such as Horng (2007), Brooks (2001), Poon and Fung (2000), Christie (1982), French, Schwert and Stambaugh (1987), Campell and Hentschel (1992), Koutmos and Booth (1995) and Koutmos (1996). Research on the relation between stock market and the return volatility method, using multivariate GARCH model, has been growing like mushroom. For examples, Yang (2005), Yang and Doong (2004), Granger, Hung and Yang (2000), Wang and Barrett (2002) and Bollerslev (1990) have applied various bivariate GARCH models analyzing stock market price.

The purpose of this paper is to examine the relations of Italy's stock market and Germany's stock market, using the DCC and the bivariate asymmetric-GARCH model in constructing the connection of the two stock markets. And using the positive and negative values of stock retrurns' volatility are as the threshold. The organization of this paper is as follows: Section 2 descibes the series character of Italy and Germany stock prices and their returns volatility; Section 3 introduces the model of the DCC and the bivariate GARCH; Section 4 presents the asymmetric test of the DCC and the bivariate-IGARCH model; Section 5 presents the model of the DCC and the bivariate asymmetric-GARCH and its parameters' estimation, and the analysis between associated of Italy and Germany stock returns; Finally, section 6 summarizes the conclusions and suggestions of this study.

\section{Data characteristics}

\subsection{Data sources}

The data of this research included the oil price, Italy and Germany’s stock price collected between January 3, 2000 and June 30, 2008. The source of the stock data was the Taiwan Economic Journal (TEJ), a database in Taiwan. Italy stock price refers to the MIBTEL stock index, and Germany's stock price refers to DX stock index. During the process of data analysis, in case that there was no stock market price available on the side of Italy's stock market or Germany's stock market due to holidays, the identical time stock price data from one side was deleted. After this, the three variables samples are 2,141.

\subsection{Returns calculation and trend charts}

To compute the return of Italy stock market, the authors adopt the natural logarithm difference, and ride 100 again. The return of Germany's stock market also derived from the natural logarithm difference, rides 100 again. Fig. 1 shows the trend charts of Italy's stock price index (ITA) (see Fig. 1a), Germany's stock price index (GER) (see Fig. 1b), the trend charts of Italy's stock price index return (RITA) (see Fig. 1c) and Germany's stock price 
index return (RGER) (see Fig. 1d) in the sample period.

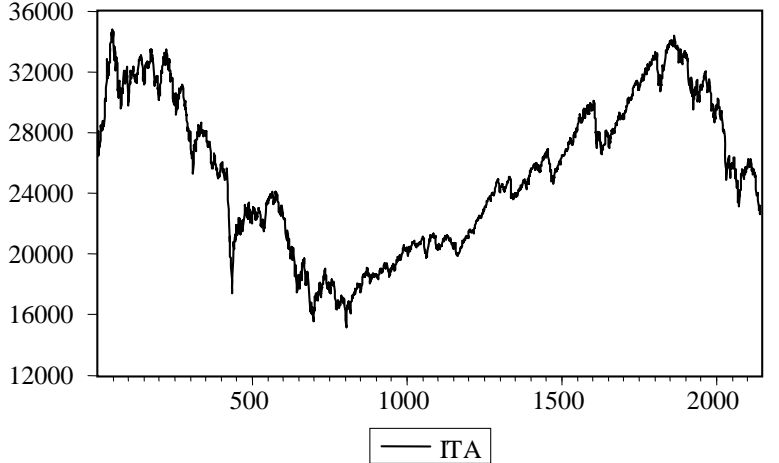

Fig. 1a

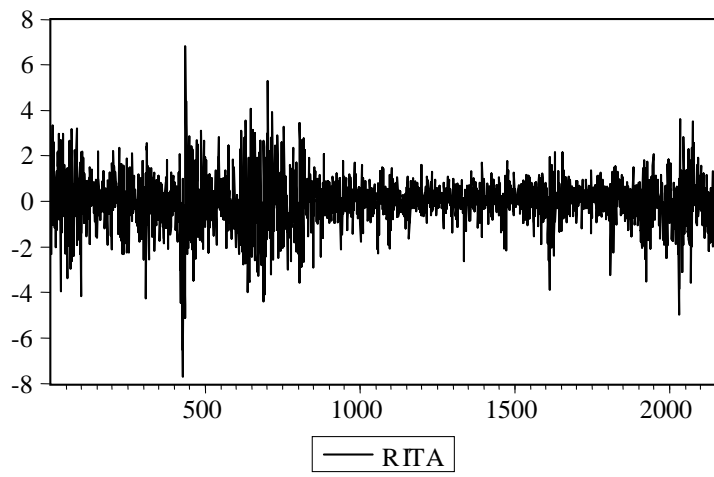

Fig. 1c

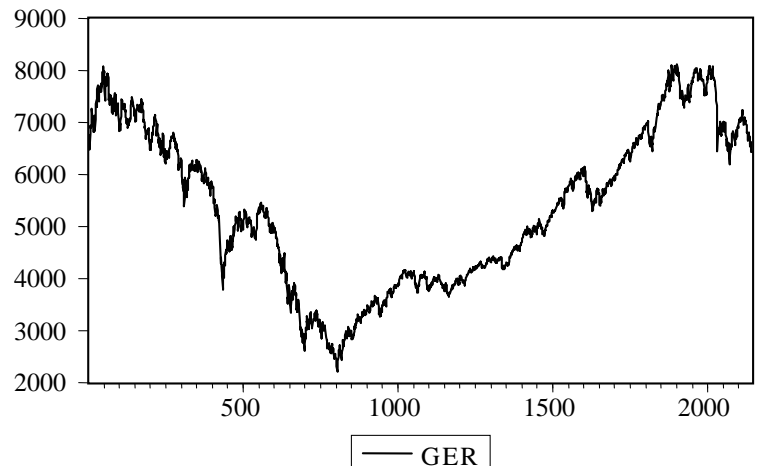

Fig. 1b

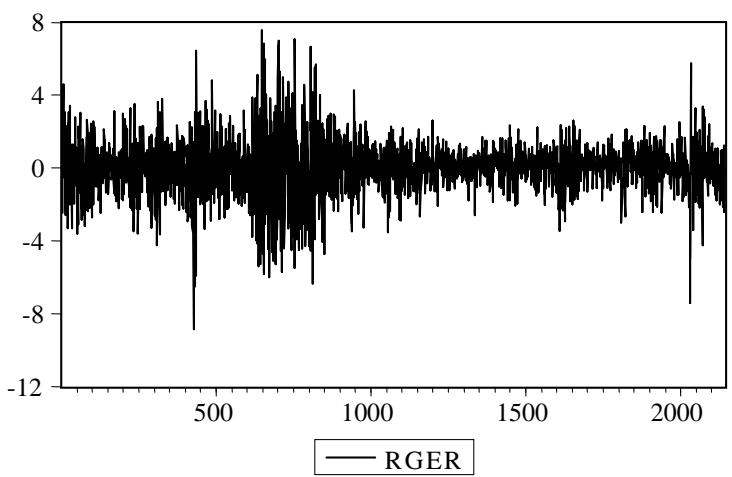

Fig. 1d

Fig. 1 Trend charts of Italy and Germany's stock price index and its return

As can be seen in Fig. 1, in the selected sample period, Italy's stock price index and Germany's stock price index obviously show the same direction of the trend. When the fluctuation of Germany's stock price index grew bigger, Italy's market return volatility degree will also became bigger. In addition, the clustering of Italy and Germany's stock price return volatility showed the same pattern. It seems that the two stock markets have a certain level of relevance. In other words, the two stock prices markets seemed to be interdependent. This is also the main motive for discussing the relationships of Italy and Germany’s stock price returns.

\subsection{Basic statistics}

Table 1 presents the basic statistics of the analysis including the mean values, standard deviations, skewed coefficients, kurtosis coefficients and the Jarque-Bera normal distribution test for the sampled period of the oil price volatility, Italy and Germany's stock market returns. The kurtosis coefficients were worth mentioning. The two return sequences' kurtosis coefficients are both bigger than 3, which implies that the normal distribution test of Jarque-Bera is not normal distribution. Although the violation of normal distribution is not uncommon for financial commodity variable, it is more appropriate to carry out the analysis, using the heavy tail distribution and the GARCH model. Also the results from ADF and KSS unit root tests indicated that the two stock markets return variables were in a stable sequence. The stable characteristic analyzes the essential condition of the GARCH model.

\subsection{Unit root test}


Furthermore, this study uses ADF (Augmented Dickey \& Fuller, 1979; Augmented Dickey \& Fuller, 1981) and KSS (Kapetanios, et al., 2003) unit root when examining the U.S. stock price index and Canada's stock price index, and deciding whether the unit root characteristic, used to examine whether the time series data has stability, not as for appears the false return (spurious regression). As shown in Table 2, the first order difference after the time series data was analyzed at the significance level of $0.01(\alpha=1 \%)$. The material the researchers used was in a stable condition. In other words, the stock returns of Italy and Germany are in stationary sequence.

Table 1 Data statistics

\begin{tabular}{ccccc}
\hline Statistics & ITA & GER & RITA & RGER \\
\hline Mean & $25,335.380$ & $5,350.287$ & -0.009919 & -0.002360 \\
S-D & $5,013.241$ & $1,519.280$ & 1.133940 & 1.563838 \\
Skewed & -0.017568 & 0.022676 & -0.372410 & -0.115883 \\
Kurtosis & 1.820273 & 1.845445 & 6.702580 & 6.073558 \\
J-B N & 124.2663 & 119.0979 & $1,271.860$ & 847.126 \\
(p-value) & $(0.0000)$ & $(0.0000)$ & $(0.0000)$ & $(0.0000)$ \\
sample & 2,141 & 2,141 & 2,140 & 2,140 \\
\hline
\end{tabular}

Notes: J-B N is the normal distribution test of Jarque-Bera; S-D denotes the standard deviation; $p$-value $<\alpha$ denote significance $(\alpha=1 \%)$.

Table 2 Unit root test of ADF and KSS for the return data

\begin{tabular}{|c|c|c|c|c|}
\hline $\mathrm{ADF}$ & ITA & GER & RITA & RGER \\
\hline Statistic & -1.3367 & -1.4148 & $-21.2619 * * *$ & $-9.6747 * * *$ \\
\hline Critical value & -3.9623 & -3.4119 & -3.1279 & \\
\hline (Significant level) & $(\alpha=1 \%)$ & $(\alpha=5 \%)$ & $(\alpha=10 \%)$ & \\
\hline KSS & ITA & GER & RITA & RGER \\
\hline Statistic & -1.3790 & -1.3007 & $-21.9386 * * *$ & $-27.1345^{* * *}$ \\
\hline Critical value & -2.820 & -2.220 & -1.920 & \\
\hline (Significant level) & ( $\alpha=1 \%)$ & ( $\alpha=5 \%)$ & $(\alpha=10 \%)$ & \\
\hline
\end{tabular}

Notes: ${ }^{* * *}$ denotes significance at the level $1 \%$.

\subsection{Co-integration test}

Using Johansen’s (1991) co-integration test as illustrated in Table 3 at the significance level of 0.05 ( $\alpha=5 \%)$ does not reveal of $\lambda_{\max }$ and Trace statistics. This indicated that Italy's stock market and Germany's stock market do not have co-integrated relation. Although the two stock markets do not seem to have a long-term co-integrated relation, the results implied that there was a mutual affect between the two markets in Table 4 . Therefore, it is necessary to further understand the gearing relation between the two markets.

Table 3 Johansen co-integration test (the lag of VAR is 5)

\begin{tabular}{ccccc}
\hline$H_{0}$ & $\lambda_{\max }$ & Critical value $(\alpha=5 \%)$ & Trace & Critical value $(\alpha=5 \%)$ \\
\hline None & 6.4541 & 16.87 & 9.3328 & 18.17 \\
At most 1 & 2.8787 & 3.74 & 2.8787 & 3.74 \\
\hline
\end{tabular}

Notes: The lag of VAR is selected by the AIC rule (Akaike, 1973). 
Return threshold model analysis of two stock markets: Evidence study of Italy and Germany's stock returns

Table 4 Unconditional correlation matrix of Italy and Germany

\begin{tabular}{cccccc}
\hline Coefficient & ITA & GER & Coefficient & RITA & RGER \\
\hline ITA & 1 & 0.9258 & RITA & 1 & 0.8186 \\
GER & 0.9258 & 1 & RGER & 0.8186 & 1 \\
\hline
\end{tabular}

\subsection{ARCH effect test}

Further examination, using the ARCH effect test, was conducted to determine whether the stock return volatility has the conditionally heteroskedasticity. This research used the Ljung-Box (1978) test method, the Lagrange multiplier (LM) test method proposed by Engle (1982) and the $F$ distribution test method proposed by Tsay (2004). These methods were used to further confirm residual error sequence variance and decided whether there was the ARCH effect. In case of the presence of the ARCH effect, the GARCH model would be used to match suitably. The ARCH effect test uses the past $q$ time lags of the residual error square to carry out the regression analysis. The ARCH effect test is based on the AR (3) model in the equation (4) and equation (5) as below. Its mathematial form is as follows:

$$
\hat{a}_{t}^{2}=d_{0}+d_{1} \hat{a}_{t-1}^{2}+\cdots+d_{q} \hat{a}_{t-q}^{2}+v_{t}
$$

The authors test the null hypotheses $H_{0}: d_{1}=d_{2}=\cdots=d_{q}=0$ by equation (1). When $\mathrm{H}_{0}$ is rejected, it implies that there is no effect of ARCH, that is, we can use the model of the GARCH to fit it.

LM, $F$ and Ljung-Box (L-B) test methods were employed to examine the stock price date return and examine whether there was the conditionally heteroskedasticity phenomenon. The examination result of the ARCH effect test is listed in Table 5. As illustrated, Italy and Germany's stock price return analysis model revealed that the series at the level of 0.05 ( $\alpha=5 \%)$ has the conditionally heteroskedasticity phenomenon. This suggested that matched suitably analysis model may use the GARCH model.

Table 5 ARCH effect test

\begin{tabular}{cccccc}
\hline Italy & Engle LM test & Tsay $F$ test & L-B test $L B^{2}(3)$ & $L B^{2}(6)$ & $L B^{2}(7)$ \\
\hline Statistic & 649.5550 & 16.3513 & 7.4734 & 4.3864 & 4.6694 \\
(p-value) & $(0.0000)$ & $(0.0000)$ & $(0.0000)$ & $(0.0000)$ & $(0.0000)$ \\
\hline \hline Germany & Engle LM test & Tsay $F$ test & L-B test $L B^{2}(2)$ & $L B^{2}(3)$ & $L B^{2}(6)$ \\
\hline Statistic & 765.2830 & 22.1981 & 5.4929 & 6.7692 & 5.4727 \\
(p-value) & $(0.0000)$ & $(0.0000)$ & $(0.0000)$ & $(0.0000)$ & $(0.0000)$ \\
\hline
\end{tabular}

Notes: $p$-value $<\alpha$ denotes significance ( $\alpha=1 \%$ ).

\section{GJR-GARCH and bivariate GARCH models}

If only single variable GARCH model analysis is conducted, then the stock return volatility is only allowed to change as necessary. In case like this, it is easy to neglect Italy and the Germany's stock price return volatility variance structure. It is likely to create the estimate without the efficiency and the deduction harms. Two stocks returns volatility conditional variance both favors changes as necessary. The bivariate GARCH model simultaneously considered two stock markets volatility on the time dependence. Therefore, this paper uses the bivariate GARCH model to discuss the impact that Italy's stock market return volatility has on Germany's stock market return and the relation between the two stock prices markets. 


\subsection{Introduction of GJR-GARCH model}

Glosten, Jaganathan and Runkle (1993) proposed the GJR-GARCH model. This model has the different influence of the good and bad news on the material volatility. The general form of GJR-GARCH model may be established as follows:

where

$$
\begin{gathered}
h_{t}=\alpha_{0}+\sum_{i=1}^{q} \alpha_{i} a_{t-i}^{2}+\eta D_{t-1} a_{t-1}^{2}+\sum_{j=1}^{p} \beta_{j} h_{t-j} \\
D_{t}= \begin{cases}0, & \text { if } a_{t}>0 \\
1, & \text { if } a_{t} \leq 0\end{cases}
\end{gathered}
$$

with $a_{t}$ is white noise, $a_{t}>0$ denotes good news, and $a_{t} \leq 0$ denotes bad news.

Regarding the GJR-GARCH model, under the good news and bad news, the influences of the condition error square item are dissimilar. Take an example with $q=1$, when there appears the good news, the error square items' volatility coefficient is $\alpha_{1}$; When appears the bad news, the error square items' volatility coefficient is $\alpha_{1}+\eta$. When $\eta=0$, the impact response of the condition error square item is symmetrical; When $\eta \neq 0$, the impact response of the condition error square item is asymmetrical, at this time, the effect is called the asymmetric effect.

\subsection{DCC and bivariate GARCH model}

From the inspectation of the results from the above-mentioned tables, it is known that Italy and Germany's stock return both have the conditionally heteroskedasticity, lepokurtic and the stationary sequence statistical characteristic. Therefore, it is suggested that the bivariate GARCH model should be used to analyze the relations between Italy and Germany's stock market returns. In this paper, the DCC and bivariate GARCH model proposed by Engle (2002) and Tse and Tusi (2002) are used to analyze the connection between Italy and Germany's stock price returns. The result of the normal distribution test of Jarque-Bera shows that the study data is not a normal distribution. In addition, the kurtosis coefficients are bigger than 3. We should use distribution of the heavy tails and it is comparatively suitable. Therefore, this paper uses the Student's $t$ distribution of heavy tails, and uses the maximum likelihood algorithm method of BHHH (Berndt, et al., 1974) to estimate the unknown parameters. The bivariate GARCH model may be constructed from equation (4) to equation (11). This model is used as a baseline to discuss Italy's stock price return volatility and its impact on Germany's stock price return. The GARCH $(1,2)$ models are stated as follows:

$$
\begin{gathered}
\operatorname{RITA}_{t}=\phi_{10}+\sum_{j=1}^{n} \phi_{1 j} R I T A_{t-j}+\sum_{j=1}^{n} \phi_{2 j} R G E R_{t-j}+a_{1, t} \\
R G E R_{t}=\varphi_{10}+\sum_{j=1}^{n} \varphi_{1 j} R G E R_{t-j}+\sum_{j=1}^{n} \varphi_{2 j} R_{T T A_{t-j}}+a_{2, t} \\
h_{11, t}=\alpha_{10}+\alpha_{11} a_{1, t-1}^{2}+\alpha_{12} a_{1, t-2}^{2}+\beta_{11} h_{11, t-1} \\
h_{22, t}=\alpha_{20}+\alpha_{21} a_{2, t-1}^{2}+\alpha_{22} a_{2, t-2}^{2}+\beta_{21} h_{22, t-1} \\
h_{12, t}=\rho_{t} \sqrt{h_{11, t}} \sqrt{h_{22, t}} \\
\rho_{t}=\exp \left(q_{t}\right) /\left(\exp \left(q_{t}\right)+1\right) \\
q_{t}=\gamma_{0}+\gamma_{1} \rho_{t-1}+\gamma_{2} a_{1, t-1} a_{2, t-1} / \sqrt{h_{11, t-1} h_{22, t-1}}
\end{gathered}
$$

$\vec{a}_{t}^{\prime}=\left(a_{1, t}, a_{2, t}\right)$ obey the bivariate Student's t distribution, this is, $T_{v}\left(\overrightarrow{0},(v-2) H_{t} / v\right)$, among $\overrightarrow{0}^{\prime}=(0,0)$ and 
$H_{t}=\left[\begin{array}{ll}h_{11, t} & h_{12, t} \\ h_{21, t} & h_{22, t}\end{array}\right], h_{12, t}=h_{21, t}$, and $v$ is the degree of freedom of Student's $t$ distribution. The probability density function of $\vec{a}_{t}$ is referred in the book of Tsay (2004). The $\rho_{t}$ is the dynamic conditional correlation coefficient of $a_{1, t}$ and $a_{2, t}$.

\section{Model estimation and analysis}

\subsection{Bivariate GARCH model and its parameter estimation}

This section uses the DCC and bivariate GARCH model, i.e., equation (4) to equation (10) to analyze the relatedness of Italy and Germany's stock price return volatilities. The empirical results show that Italy and Germany's stock price return volatility may be based on the DCC and bivariate IGARCH $(1,2)$ model. Its estimate results are in Table 6.

Table 6 DCC and estimation of the bivariate IGARCH $(1,2)$ model

\begin{tabular}{|c|c|c|c|c|c|}
\hline Parameters & $\phi_{10}$ & $\phi_{13}$ & $\phi_{23}$ & $\varphi_{10}$ & $\varphi_{13}$ \\
\hline Coefficient & 0.0779 & 0.0680 & -0.0601 & 0.0976 & -0.0977 \\
\hline (p-value) & $(0.0000)$ & $(0.0526)$ & $(0.0124)$ & $(0.0000)$ & $(0.0025)$ \\
\hline Parameters & $\varphi_{23}$ & $\alpha_{10}$ & $\alpha_{11}$ & $\alpha_{12}$ & $\beta_{11}$ \\
\hline Coefficient & 0.1190 & 0.0082 & 0.0362 & 0.0474 & 0.9164 \\
\hline (p-value) & $(0.0046)$ & $(0.0001)$ & $(0.0238)$ & $(0.0079)$ & $(0.0000)$ \\
\hline Parameters & $\alpha_{20}$ & $\alpha_{21}$ & $\alpha_{22}$ & $\beta_{21}$ & $v$ \\
\hline Coefficient & 0.0158 & 0.0583 & 0.0255 & 0.9162 & 6.6373 \\
\hline (p-value) & $(0.0001)$ & $(0.0129)$ & $(0.3196)$ & $(0.0000)$ & $(0.0000)$ \\
\hline Parameters & $\gamma_{0}$ & $\gamma_{1}$ & $\gamma_{2}$ & $\bar{\rho}_{t}$ & \\
\hline Coefficient & 7.4184 & -6.7024 & 0.0035 & 0.8493 & \\
\hline (p-value) & $(0.0002)$ & $(0.0040)$ & $(0.7990)$ & $(0.0000)$ & \\
\hline
\end{tabular}

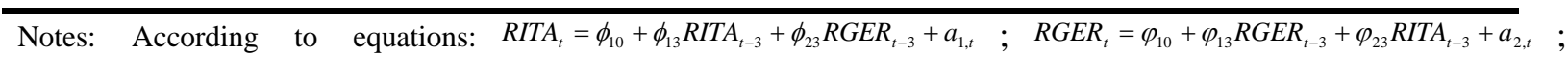
$h_{11, t}=\alpha_{10}+\alpha_{11} a_{1, t-1}^{2}+\alpha_{12} a_{1, t-2}^{2}+\beta_{11} h_{11, t-1} ; h_{22, t}=\alpha_{20}+\alpha_{21} a_{2, t-1}^{2}+\alpha_{22} a_{2, t-2}^{2}+\beta_{21} h_{22, t-1} ; \quad q_{t}=\gamma_{0}+\gamma_{1} \rho_{t-1}+\gamma_{2} a_{1, t-1} a_{2, t-1} / \sqrt{h_{11, t-1} h_{22, t-1}} ;$ $\rho_{t}=\exp \left(q_{t}\right) /\left(\exp \left(q_{t}\right)+1\right) ; h_{12, t}=\rho_{t} \sqrt{h_{11, t}} \sqrt{h_{22, t}}$.

$p$-value $<\alpha$ denotes significance ( $\alpha=1 \%, \alpha=5 \%, \alpha=10 \%$ ); The minimum estimated value of conditional correlation coefficient equals $\hat{\bar{\rho}}_{t}=0.7121$ and the maximum estimated value of conditional correlation coefficient equals $\hat{\bar{\rho}}_{t}=0.9719$; The maximum likelihood function value of natural logarithm equals $L_{f}=-2701.0777$.

\subsection{Diagnosis analysis of asymmetric for the bivariate IGARCH model}

Because of the parameter estimation and the standard residual error diagnosis in the below DCC and bivariate IGARCH $(1,2)$ model, the examination can only check if the model matches up with the suitable quality, but it is actually unable to look up whether the model has an asymmetrical phenomenon. Therefore, Engle and Ng (1993) develop a diagnosis test in order to examine whether the model has asymmetrical risk or not. This research uses this diagnosis test to carry out the examination.

Engle and Ng (1993) believe that by observing the variables' past value, it is possible to forecast the 
standardized residual error square $\left(a_{t} / \sigma_{t}\right)^{2}, \sigma_{t}=\left(h_{t}(v-2) / v\right)^{1 / 2}$. However, if there is no forecast pattern of the variables' past value, then the expression model may be set up mistakenly. Therefore, the examination method of the model hypotheses has the following four examination methods:

(1) Sign bias test:

(2) Negative size bias test:

$$
\left(a_{t} / \sqrt{h_{t}}\right)^{2}=b_{0}+b_{1} S_{t-1}^{-}+e_{t}
$$

$$
\left(a_{t} / \sqrt{h_{t}}\right)^{2}=b_{0}+b_{1} S_{t-1}^{-}\left(a_{t-1} / \sqrt{h_{t-1}}\right)+e_{t}
$$

(3) Positive size bias test:

$$
\left(a_{t} / \sqrt{h_{t}}\right)^{2}=b_{0}+b_{1}\left(1-S_{t-1}^{-}\right)\left(a_{t-1} / \sqrt{h_{t-1}}\right)+e_{t}
$$

(4) Joint test:

$$
\left(a_{t} / \sqrt{h_{t}}\right)^{2}=b_{0}+b_{1} S_{t-1}^{-}+b_{2} S_{t-1}^{-}\left(a_{t-1} / \sqrt{h_{t-1}}\right)+b_{3}\left(1-S_{t-1}^{-}\right)\left(a_{t-1} / \sqrt{h_{t-1}}\right)+e_{t}
$$

where $S_{t-1}^{-}$is the dummy variable, as $a_{t} \leq 0$, then $S_{t-1}^{-}=1 ; a_{t}>0$, then $S_{t-1}^{-}=0$.

After the above four of examination results, Table 7 asymmetrically examines the result for Italy's stock price market as: (1) the sign bias test reveals ( $\alpha=1 \%$ ); (2) the negative size bias test reveals ( $\alpha=1 \%$ ); (3) the positive size bias test reveals ( $\alpha=1 \%$ ); (4) the joint test reveals ( $\alpha=1 \%$ ). And Table 7 also asymmetrically examines the result for the Germany's stock price market as: (1) the sign bias test reveals ( $\alpha=1 \%$ ); (2) the negative size bias test reveals ( $\alpha=1 \%$ ); (3) the positive size bias test reveals ( $\alpha=1 \%$ ); (4) the joint test reveals ( $\alpha=1 \%$ ). By the positive size bias test and the joint test, it shows that Italy and Germany's stock price markets do have the asymmetry effects.

Table 7 Asymmetric test of the bivariate $\operatorname{IGARCH}(1,2)$

\begin{tabular}{ccccc}
\hline Italy & Sign bias test & Negative size bias test & Positive size bias test & Joint test \\
\hline F statistic & 10.9911 & 13.5719 & 13.9452 & 10.4731 \\
(p-value) & $(0.0009)$ & $(0.0002)$ & $(0.0002)$ & $(0.0000)$ \\
\hline \hline Germany & Sign bias test & Negative size bias test & Positive size bias test & Joint test \\
\hline$F$ statistic & 17.3966 & 17.3307 & 10.8075 & 13.0028 \\
(p-value) & $(0.0000)$ & $(0.0000)$ & $(0.0000)$ & $(0.0000)$ \\
\hline
\end{tabular}

Notes: $p$-value $<\alpha$ denotes significance ( $\alpha=1 \%, \alpha=5 \%, \alpha=10 \%$ ).

\section{DCC and bivariate asymmetric-GARCH model and model checking}

\subsection{DCC and bivariate asymmetric-GARCH model and parameter estimation}

Based on the results of the positive size bias test and the joint test, we may use the GARCH model of asymmetric to discuss Italy and Germany's stock price return volatility process. Following the idea of GJR-GARCH model, the use of the positive and negative value of Italy and Germany's stock return volatility is a threshold, respectively. After model process selection, in this paper, we may use the asymmetric-GARCH $(1,2)$ model to discuss the volatility model construction of the Italy's and the Germany's stock price return, the model is illustrated as follows:

$$
\begin{gathered}
\text { RITA }_{t}=u_{t-1}\left(\phi_{10}+\phi_{13} \text { RITA }_{t-3}+\phi_{23} R_{\text {RER }}+a_{1, t}\right)+ \\
\left(1-u_{t-1}\right)\left(\phi_{20}+\phi_{13}^{\prime} \text { RITA }_{t-3}+\phi_{23}^{\prime} R R_{t-3}+a_{1, t}\right)
\end{gathered}
$$




$$
\begin{aligned}
& R G E R_{t}=w_{t-1}\left(\varphi_{10}+\varphi_{13} R G E R_{t-1}+\varphi_{23} R_{T T A_{t-3}}+a_{2, t}\right)+ \\
& \left(1-w_{t-1}\right)\left(\varphi_{20}+\varphi_{13}^{\prime} R G E R_{t-3}+\varphi_{23}^{\prime} R_{T T A_{t-3}}+a_{2, t}\right) \\
& h_{11, t}=u_{t-1}\left(\alpha_{10}+\alpha_{11} a_{1, t-1}^{2}+\alpha_{12} a_{1, t-2}^{2}+\beta_{11} h_{11, t-1}\right)+\left(1-u_{t-1}\right)\left(\alpha_{12}^{\prime} a_{1, t-2}^{2}+\beta_{11}^{\prime} h_{11, t-1}\right) \\
& h_{22, t}=w_{t-1}\left(\alpha_{20}+\alpha_{21} a_{2, t-1}^{2}+\alpha_{22} a_{2, t-2}^{2}+\beta_{21} h_{22, t-1}\right)+\left(1-w_{t-1}\right)\left(\alpha_{22}^{\prime} a_{2, t-2}^{2}+\beta_{21}^{\prime} h_{22, t-1}\right) \\
& h_{12, t}=\rho_{t} \sqrt{h_{11, t}} \sqrt{h_{22, t}} \\
& \rho_{t}=\exp \left(q_{t}\right) /\left(\exp \left(q_{t}\right)+1\right) \\
& q_{t}=\gamma_{0}+\gamma_{1} \rho_{t-1}+\gamma_{2} a_{1, t-1} a_{2, t-1} / \sqrt{h_{11, t-1} h_{22, t-1}} \\
& u_{t}=\left\{\begin{array}{ll}
1, & \text { if } R_{T T A_{t-1}} \leq 0 \\
0, & \text { if } \text { RITA }_{t-1}>0
\end{array}, w_{t}= \begin{cases}1, & \text { if } R G E R_{t-1} \leq 0 \\
0, & \text { if } R G E R_{t-1}>0\end{cases} \right.
\end{aligned}
$$

with $R C A N A_{t}>0$ and $R U S A_{t}>0$ denote good news, $R C A N A_{t} \leq 0$ and $R U S A_{t} \leq 0$ denote bad news. The white noise of $\vec{a}_{t}^{\prime}=\left(a_{1, t}, a_{2, t}\right)$ also obeys the bivariate Student's $t$ distribution and its function form is defined as above.

This section uses the DCC and the bivariate asymmetric-GARCH model, namely uses equation (15) to equation (22), to discuss Italy's and Germany's stock price return volatilities' relatedness analysis. Parameters' estimation firstly considers a general model, and bases on the estimated results. Then, the authors delete some nonsignificant explanation variables, and finally obtain a simplification model for Italy and Germany's stock price return volatilities' relatedness analysis. From the empirical diagnosis result, we know that Italy and Germany's stock price return volatility may be constructed on the DCC and bivariate asymmetric-GARCH $(1,2)$ model. Its estimate result is stated in Table 8. Based on the estimated results of the DCC and the bivariate asymmetric-GARCH $(1,2)$ model in Table 8, the authors test the estimated value of parameters' coefficient to be significant or not with a $p$-value.

Under the bad news and the good news, the observation condition's constant term coefficient does have significant influence under the $10 \%$ significance level in Italy. If the investors have a long-term view on an investment stock in Italy, they are able to obtain a certain degree of return. Under the bad news, Italy's stock price return receives before 3 days' impact of Italy's stock market return $\left(\phi_{13}=0.0720\right)$. Under the good news, Italy's stock price return volatility does also receive before 3 days' influence of Germany's stock price return ( $\left.\phi_{23}^{\prime}=-0.0645\right)$.

Under the bad news, the observed mean equation of the estimated coefficient demonstrates that the observation condition's constant term coefficient does have significant influence under the $10 \%$ significance level in Germany. If the investors have a long-term view on an investment stock in Germany, they are able to obtain a certain degree of return. Under the bad news and good news, Germany's stock price return receives before 3 days' impact of Italy ( $\varphi_{23}=0.1657$ and $\varphi_{23}^{\prime}=0.0710$, respectively). Under the bad news, Germany's stock price return receives before 3 days' impact of Germany's stock market return ( $\left.\varphi_{13}=-0.1593\right)$.

On the other hand, the correlation coefficient average estimation value $\left(\hat{\bar{\rho}}_{t}=0.8424\right)$ of Italy and Germany's stock price return volatility is significant. This result also shows that Italy's stock price return volatility is the positive influence to Germany's stock price return's volatility, and they are precisely the synchronized mutual influence. When the variation risks of Italy's stock price return increases, the investors' risk of Germany's stock price return is able to increase. Likewise, when the variation risks of Italy's stock price return reduce, the investors' risk of the Germany's stock price return is also able to reduce. In addition, the estimated value of the degree of freedom for the 
Student's $t$ distribution is 6.7345, and is significant under the significance level of 0.01 ( $\alpha=1 \%$ ). This also demonstrates that this research data has the heavy-tailed distribution. This results as above are consistent to the estimated results of the bivariate IGARCH $(1,2)$ model.

The observed conditional variance equation of the estimated coefficient, under the $10 \%$ significance level, demonstrates that all the conditional variance estimated coefficients are significant in Table 8. From the Table 8, the estimated coefficients of the conditional variance equation will produce different variation risks under bad news and good news. We have the results that $\alpha_{11}+\alpha_{12}+\beta_{11}=1, \alpha_{12}^{\prime}+\beta_{11}^{\prime}=0.8982, \alpha_{21}+\alpha_{22}+\beta_{21}=1$ and $\alpha_{22}^{\prime}+\beta_{21}^{\prime}=0.9135$. This results conforms the assumed conditions of the IGARCH model and GARCH model, respectively. This result also demonstrates that the DCC and the bivariate asymmetric-GARCH $(1,2)$ model may catch Italy and Germany's stock price return volatilities’ process. But this model also needs further research to carry on the diagnostic analysis of the standard residual error, and the detail will be provided as below. Under the bad news, Italy's stock market has a fixed variation risk and Germany's stock market has also the fixed variation risk. Besides, taking the good news as a sample, Italy and Germany's stock market returns have different conditional variable risks (respectively, $\beta_{11}^{\prime}=0.7820$ and $\beta_{21}^{\prime}=0.8314$ ). This demonstrates that both the good news and bad news of the stock returns' volatility will produce the different variation risks of Italy and Germany’s stock price markets. Based on the likelihood ratio test, the test result is also supported the bivariate asymmetric-GARCH $(1,2)$ model in Table 8. Therefore, the explanatory ability of the DCC and the bivariate asymmetric-GARCH $(1,2)$ model is better than the model of the DCC and the bivariate IGARCH $(1,2)$.

Table 8 Parameter estimation of the DCC and the bivariate asymmetric-GARCH $(1,2)$ model

\begin{tabular}{|c|c|c|c|c|c|c|}
\hline Parameters & $\phi_{10}$ & $\phi_{13}$ & $\phi_{23}$ & $\phi_{20}$ & $\phi_{13}^{\prime}$ & $\phi_{23}^{\prime}$ \\
\hline Coefficient & 0.0542 & 0.0720 & -0.0466 & 0.0448 & 0.0523 & -0.0645 \\
\hline (p-value) & $(0.0118)$ & $(0.0982)$ & $(0.1125)$ & $(0.0127)$ & $(0.1855)$ & (0.0119) \\
\hline Parameters & $\varphi_{10}$ & $\varphi_{13}$ & $\varphi_{23}$ & $\varphi_{20}$ & $\varphi_{13}^{\prime}$ & $\varphi_{23}^{\prime}$ \\
\hline Coefficient & 0.0974 & -0.1593 & 0.1657 & 0.0342 & -0.0416 & 0.0710 \\
\hline (p-value) & $(0.0004)$ & $(0.0001)$ & $(0.0015)$ & (0.1569) & $(0.2292)$ & $(0.0975)$ \\
\hline Parameters & $\alpha_{10}$ & $\alpha_{11}$ & $\alpha_{12}$ & $\beta_{11}$ & $\alpha_{12}^{\prime}$ & $\beta_{11}^{\prime}$ \\
\hline Coefficient & 0.1212 & 0.1208 & 0.1367 & 0.7425 & 0.1162 & 0.7820 \\
\hline (p-value) & $(0.0000)$ & $(0.0000)$ & $(0.0000)$ & $(0.0000)$ & $(0.0000)$ & $(0.0000)$ \\
\hline Parameters & $\alpha_{20}$ & $\alpha_{21}$ & $\alpha_{22}$ & $\beta_{21}$ & $\alpha_{22}^{\prime}$ & $\beta_{21}^{\prime}$ \\
\hline Coefficient & 0.1917 & 0.0916 & 0.1321 & 0.7763 & 0.0821 & 0.8314 \\
\hline (p-value) & $(0.2587)$ & $(0.0002)$ & $(0.0000)$ & $(0.0000)$ & (0.0003) & $(0.0000)$ \\
\hline Parameters & $\gamma_{0}$ & $\gamma_{1}$ & $\gamma_{2}$ & $v$ & $\bar{\rho}_{t}$ & \\
\hline Coefficient & -2.2099 & 5.5336 & 0.0842 & 6.7345 & 0.8424 & \\
\hline & & & & & & \\
\hline
\end{tabular}

Notes: $p$-value $\alpha \alpha$ denotes significance ( $\alpha=1 \%, \alpha=5 \%, \alpha=10 \%$ ); The minimum estimated value of conditional correlation coefficient equals $\hat{\bar{\rho}}_{t}=0.6021$ and the maximum estimated value of conditional correlation coefficient equals $\hat{\bar{\rho}}_{t}=1.0000$; The maximum likelihood function value of natural logarithm equals $L_{f}=-2672.8992$ and $-2\left[L_{f}-L_{r}\right]=56.3570 . \quad \chi_{0.10}^{2}(10)=15.9872$, $\chi_{0.05}^{2}(10)=18.3070, \quad \chi_{0.01}^{2}(10)=23.2093$.

\subsection{Model checking of the standard residual for the DCC and bivariate asymmetric-GARCH model}


To correct the inappropriateness of the DCC and the bivariate asymmetric-GARCH model, Ljung-Box test method is used to further examine the standard residual error and a standard residual error square item and to see whether there still exists auto-correlation. Tables 9 shows the $Q$ test of the standard residual error and $Q$ test of the standard residual error square item with a $p$-value. Clearly, this model does not have the auto-correlation. From Tables 10, we can see that the proposed model does not have the ARCH effects of standard residual error square item. Therefore, the DCC and bivariate asymmetric-GARCH $(1,2)$ model matches quite suitably and is more appropriate.

Table 9 L-B $Q$ test of standard residual and standard residual square item of the DCC and bivariate asymmetric-GARCH $(1,2)$

\begin{tabular}{cccccccc}
\hline \multirow{3}{*}{ Italy } & L-B test & $L B(10)$ & $L B(20)$ & $L B(25)$ & $L B^{2}(10)$ & $L B^{2}(20)$ & $L B^{2}(25)$ \\
\cline { 2 - 8 } & $Q$ statistic & 8.7260 & 11.9710 & 13.9798 & 10.6227 & 17.9849 & 18.5225 \\
& $(\mathrm{p}$-value) & $(0.5583)$ & $(0.9171)$ & $(0.9621)$ & $(0.3877)$ & $(0.5884)$ & $(0.8194)$ \\
\hline \hline \multirow{3}{*}{ Germany } & L-B test & $L B(10)$ & $L B(20)$ & $L B(25)$ & $L B^{2}(10)$ & $L B^{2}(20)$ & $L B^{2}(25)$ \\
\cline { 2 - 8 } & Q statistic & 11.8106 & 22.9614 & 25.5028 & 9.4490 & 14.9855 & 18.0959 \\
& $(\mathrm{p}$-value) & $(0.2979)$ & $(0.2907)$ & $(0.4345)$ & $(0.4901)$ & $(0.7772)$ & $(0.8383)$ \\
\hline
\end{tabular}

Notes: $p$-value $<\alpha$ denotes significance ( $\alpha=1 \%, \alpha=5 \%, \alpha=10 \%$ ).

Table 10 ARCH effect (L-B) test of the standard residual of the DCC and bivariate asymmetric-GARCH $(1,2)$

\begin{tabular}{cccccc}
\hline Italy & $L B^{2}(10)$ & $L B^{2}(20)$ & $L B^{2}(30)$ & $F$ test & \\
\hline$Q$ statistic & 0.8349 & 0.2109 & 0.2844 & Statistic & 0.7125 \\
(p-value) & $(0.4039)$ & $(0.8330)$ & $(0.7761)$ & (p-value) & $(0.8747)$ \\
\hline \hline Germany & $L B^{2}(10)$ & $L B^{2}(20)$ & $L B^{2}(30)$ & $F$ test & 0.6412 \\
\hline$Q$ statistic & 0.7583 & 0.3152 & 0.0617 & Statistic & $(0.9340)$ \\
(p-value) & $(0.4484)$ & $(0.7526)$ & $(0.9508)$ & (p-value) & \\
\hline
\end{tabular}

Notes: $p$-value $<\alpha$ denotes significance ( $\alpha=1 \%, \alpha=5 \%, \alpha=10 \%$ ).

\section{Conclusions}

There are many factors that might have great influence on stock prices including overall economic agents and overall currency supplies, interest rate, price and inflation rate. Each factor may have influence on the stock price return. This research discusses two market return volatilities' influence of Italy and Germany. the authors use data from January 3, 2000 to June 30, 2008. The empirical result shows that Italy and Germany's stock price market return's volatility has an asymmetric effects, and Italy and Germany's stock price return volatility may construct in the DCC and the bivariate asymmetric-GARCH $(1,2)$ model with a threshold of oil price volatility. This model also passes through a standard residual error and the ARCH effect test. This situation demonstrates that the DCC and bivariate asymmetric-GARCH $(1,2)$ model's fitting is appropriate. The empirical result also obtains that the dynamic conditional correlation coefficient value $\left(\hat{\bar{\rho}}_{t}=0.8424\right)$ of Italy and Germany's stock price return volatility is positive. This result demonstrates that Italy's stock return volatility is affecting Germany's stock return volatility, and Germany's stock return volatility is also affecting Italy's stock return volatility. The empirical result also discovers that Italy and Germany's stock price market returns volatility has an asymmetrical phenomenon. The positive and negative values of the stock return volatility affect the variation risks of Italy and Germany's stock 
markets. Therefore, the explanation ability of the bivariate asymmetric-GARCH $(1,2)$ is better than the bivariate-IGARCH $(1,2)$ model.

However, the theory and the model discussing on the return and volatility property of financial commodity are multitudinous. This research only uses the stock price and the bivariate asymmetric-GARCH model to discuss the two stock markets of Italy and Germany. For future research, the authors suggest that other asymmetric models should be used for further analysis.

\section{References:}

Akaike, H.. (1973). Information theory and an extension of the maximum likelihood principle. In: B. N. Petrov \& F. C. (Eds.), 2nd International symposium on information theory. Budapest: Akademiai Kiado, 267-281.

Bollerslev, T.. (1986). Generalized autoregressive conditional hetroskedasticity. Journal of Econometrics, 31(3), 307-327.

Bollerslev, T.. (1990). Modeling the coherence in short-run nominal exchange rates: A multivariate generalized ARCH model. Review of Economics and Statistics, 72, 498-505.

Berndt, E. K., Hall, B. H., Hall, R. E. \& Hausman, J. A.. (1974). Estimation and inference in nonlinear structural models. Annals of Economic and Social Measurement, 3(4), 653-665.

Brooks, C.. (2001). A double-threshold GARCH model for the French Franc/Deutschmark exchange rate. Journal of Forecasting, 20(2), 135-143.

Campell, J. Y. \& Hentschel, L.. (1992). No news is good news: An asymmetric model of changing volatility in stock returns. Journal of Financial Economic, 31(3), 281-318.

Christie, A. A.. (1982). The stochastic behavior of common stock variances: Value, leverage and interest rate effects. Journal of Financial Economics, 10(4), 407-432.

Dickey, D. A. \& Fuller, W. A.. (1979). Distribution of the estimators for autoregressive time series with a unit root. Journal of the American Statistical Association, 74(366), 427-431.

Dickey, D. A. \& Fuller, W. A.. (1981). Likelihood ratio statistics for autoregressive time series with a unit root. Econometrica, 49(4), 1057-1072.

Engle, R. F.. (1982). Autoregressive conditional heteroskedasticity with estimates of the variance of United Kingdom inflation. Econometrica, 50(4), 987-1007.

Engle, R. F.. (2002). Dynamic conditional correlation-A simple class of multivariate GARCH models. Journal of Business and Economic Statistics, 20(3), 339-350.

Engle, R. F. \& Ng, V. K.. (1993). Measuring and testing the impact of news on volatility. Journal of Finance, 48(5), $1749-1777$.

French, K. R., Schwert, G. W. \& Stambaugh, R. F.. (1987). Expected stock returns and volatility. Journal of Financial Economics, 19, 3-29.

Granger, C. W., Hung, J. B. \& Yang, C. W.. (2000). A bivariate causality between stock prices and exchange rates: Evidence from recent Asian flu. The Quarterly Review of Economics and Finance, 40(3), 337-354.

Glosten, L. R., Jagannathan, R. \& Runkle, D. E.. (1993). On the relation between the expected value and the volatility on the nominal excess returns on stocks. Journal of Finance, 48(5), 1779-1801.

Horng, W. J.. (2007). An impact of the U.S. and the U.K. return rates' volatility on the stock market returns: An evidence study of Japan's stock market returns. Journal of Probability and Statistical Science, 5(2), 217-231.

Johansen, S.. (1991). Estimation and hypothesis testing of cointegration vector in Gaussian vector autoregressive models. Econometrica, 52(3), 389-402.

Kapetanios, G., Shin, Y. \& Snell, A.. (2003). Testing for a unit root in the nonlinear STAR framework. Journal of Econometrics, 112(2), 359-379.

Koutmos, G. \& Booth, G. G.. (1995). Asymmetric volatility transmission in international stock markets. Journal of International Money and Finance, 14(6), 747-762.

Koutmos, G.. (1996). Modeling the dynamic interdependence of major European stock markets. Journal of Business Finance and Accounting, 23(7), 975-988. 
Ljung, G. M. \& Box, G. E. P.. (1978). On a measure of lack of fit in time series models. Biometrika, 65(2), 297-303.

Nelson, D. B.. (1990). Stationarity and persistence in the GARCH $(1,1)$ model. Econometric Theory, 6(3), 318-334.

Nelson, D. B.. (1991). Conditional heteroscedasticity in asset returns: A new approach. Econometrica, 59(2), 347-370.

Poon, W. P. H. \& Fung, H. G.. (2000). Red chip or H shares: Which China-backed securities process information the fastest? Journal of Multinational Financial Management, 10(3-4), 315-343.

Tsay, R. S.. (2004). Analysis of financial time series. New York: John Wiley \& Sons, Inc.

Tse, Y. K. \& Tsui, Albert K. C.. (2002). A multivariate GARCH model with time-varying correlations. Journal of Business \& Economic Statistics, 20(3), 351-362.

Wang, K. L. \& Barrett, C. B.. (2002). A new look at the trade volume effects of real exchange rate risk. (Working paper No. 14751). Cornell University.

Yang, S. Y. \& Doong, S. C.. (2004). Price and volatility spillovers between stock prices and exchange rates: Empirical evidence from the G-7 countries. International Journal of Business and Economics, 3(2), 139-153.

Yang, S. Y.. (2005). A DCC analysis of international stock market correlations: The role of Japan on the Asian four tigers. Applied Financial Economics Letters, 1(2), 89-93.

(Edited by Ruby and Chris)

\section{(continued from Page 22)}

Copeland, T.. (1976). A model of asset trading under the assumption of sequential information arrival. Journal of Finance, 31, 1149-1168.

Floros, C. \& Vougas, D. V.. (2007). Trading volume and returns relationship in Greek stock index futures market: GARCH vs. GMM. International Research Journal of Finance and Economics, 12.

Foster, J.. (1995). Volume-volatility relationships for crude oil futures markets. The Journal of Futures Markets, 15, 929-951.

Girma, B. \& Mougoue M.. (2002). An empirical examination of the relation between futures spreads, volatility, volume, and open interest. The Journal of Futures Markets, 22, 1083-1102.

Gwilym, O., McMillan, D. \& Speight, A.. (1999). The intraday relationship between volume and volatility in LIFFE futures markets. Applied Financial Economics, 9, 593-604.

Karpoff, J. M.. (1987). The relation between price changes and trading volume: A survey. Journal of Financial and Quantitative Analysis, 22, 109-126.

Karpoff, J. M.. (1988). Costly short sales and the correlation of returns with volume. The Journal of Financial Research, 3.

Lamoureux, C. G. \& Lastrapes, W. D.. (1990). Heteroskedasticity in stock returns data: volume versus GARCH effects. Journal of Finance, 45, 221-229.

McMillan, D. \& Speight, A.. (2002). Returns-volume dynamics in UK futures. Applied Financial Economics, 12, 707-713.

Sharmar J.L., Mougoue, M. \& Kamath, R.. (1996). Heterskedasticity in stock market indicator return data: Volume versus GARCH effect. Applied Financial Economics, 6, 337-342.

Tauchen, G. E. \& Pitts, M.. (1983). The price variability volume relationship on speculative markets. Econometrica, 51, 485-505.

Wang, G. H. K. \& Yau, J.. (2000). Trading volume, bid-ask spread, and price volatility in futures market. Journal of Futures Markets, 20, 943-970.

(Edited by Ruby and Chris) 